\title{
Analytical Predictions on Flexural Strengthening of Reinforced Concrete Beams with Hybrid FRP Laminate
}

\author{
K. Pradeeba, A.Rajasekaran
}

\begin{abstract}
This paper presents the predicted regression equation for the study parameters of Reinforced Concrete (RC) beams strengthened with Hybrid Fibre Reinforced Polymer (HyFRP) laminate at the soffit of beam. To study the effectiveness of HyFRP laminate on flexural strengthening a total of five beams were cast and tested.The variable parameters are thickness, elastic modulus and tensile strength of HyFRP laminates. Four combinations of HyFRP laminates precisely, $90 \%$ Glass fibre + $10 \%$ Basalt fibre of thickness, $80 \%$ Glass fibre $+20 \%$ Basalt fibre, $70 \%$ Glass fibre $+30 \%$ Basalt fibre, $60 \%$ Glass fibre $+40 \%$ Basalt fibre, and their corresponding thickness were 2.78, 3.24, 3.86 and $4.24 \mathrm{~mm}$ respectively. The test results concluded that reinforced concrete beams strengthened with $70 \%$ Glass $+30 \%$ Basalt HyFRP laminate enhance the ultimate load carrying capacity of $68.97 \%$ with respect to control beam. The values reached through the predicted regression equation showed equitable accuracy with those of experimental values.
\end{abstract}

Keywords- Basalt, glass, HyFRP, laminate, regression.

\section{INTRODUCTION}

The concrete structural elements exhibits cipher of distress and deterioration at an premature age of construction due to variety of reasons, leading to repair works. Strengthening systems improve the resistance of an existing structure to internal forces either in a passive or active manner. Passive strengthening systems are typically engaged only with additional loads, beyond those existing at the time of installation are applied to the structure. Bonding steel plates or Fibre Reinforced Polymer (FRP) composites on the structural members are examples of passive strengthening systems. Active strengthening systems typically engage the structure instantaneously and may be accomplished by introducing external forces to the member that counteract the effects of internal forces. Instance of this may embrace the use of external post-tensioning systems or by jacking the member to relive or transfer the existing load. Whether passive or active, the main challenge is to achieve composite performance between the existing structure and the new strengthening concrete structural elements.

Manuscript received on September 2, 2021.

Revised Manuscript received on September 6, 2021.

Manuscript published on October 30, 2021.

* Correspondence Author

K. Pradeeba*, Research Scholar, Department of Civil and Structural Engineering, Annamalai University, Annamalai Nagar, (Tamil Nadu), India.

A.Rajasekaran, Professor, Department of Civil and Structural Engineering, Annamalai University, Annamalai Nagar, (Tamil Nadu), India.

(C) The Authors. Published by Blue Eyes Intelligence Engineering and Sciences Publication (BEIESP). This is an open access article under the CC BY-NC-ND license (http://creativecommons.org/licenses/by-nc-nd/4.0/)
One of the most common strengthening procedures was external bonding of steel plates to concrete structural members.Disadvantage of using steel is the difficulty in handling and manipulation of steel plates at site.Fibre Reinforced Polymer (FRP) is comparatively an advent technology in advanced composite materials. FRP exhibit several improved properties like high strength-weight ratio, high stiffness-weight ratio, flexibility, high fatigue potential, ease of handling and transportation, very low maintenance cost and corrosion free. Nowadays the application of FRP has been used in almost all fields. With this background the present study was taken to reveal the effectiveness of hybrid FRP on flexural strengthening of RC beams. Multiple linear regression analysis has been carried out to understand the flexural response of HyFRP strengthened reinforced concrete beams. Attariet al., (2012) conducted an experimental study to enumerate the effectiveness of hybrid FRP with combination of glass fibre and carbon in reinforced concrete beams. The authors reported the test results of seven beams and concluded that double layered glass-carbon FRP fabric strengthening system showed good results on ultimate load carrying capacity, stiffness and ductility. Hawileh et al.,(2014) examined the performance of Reinforced Concrete (RC) beams strengthened means of different combinations of externally bonded hybrid Glass and Carbon Fiber Reinforced Polymer (GFRP/CFRP) sheets at the soffit of beams. All the beams were tested under four-point bending until failure. All the beams failed under flexure mode. The ultimate enhancement of load when compared with control beam was ranged from $30 \%$ to $90 \%$. The authors proposed regression equation to predict the performance parameters and the findings of those equation are well agreed with those of experimental results. The committee report ACI 440.2R encompassed guidelines for the strengthening of structural elements in in flexure, shear, axial tension and axial compression. Chellapandianet al., (2019) evaluated the efficiency of hybrid fiber reinforced polymer (FRP) plating on the complete behavioral enhancement of reinforced concrete (RC) beams under flexure. A total of 8 RC beams were cast and strengthened using different FRP techniques including (i) near surface mounting (NSM), (ii) external bonding (EB) and (iii) hybrid strengthening using a combination of NSM carbon FRP laminates and EB CFRP fabric. The test specimens were tested under two-point loading until failure.

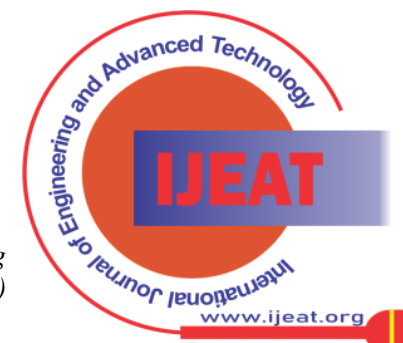


The findings concluded that enhancement in load carrying capacity was $85 \%$ which was achieved by Near Surface Mounted (NSM) technique. The predicted values through Finite Element Modeling also showed good accuracy with the experimental results.Ibrahim et al., (2020) examined the efficacy of near surface mounted hybrid carbon/glass fibre reinforced polymer (FRP) strips for strengthening of shear-deficient reinforced-concrete (RC) rectangular deep beams. The findings revealed that the NSM-FRP increased the beam shear strength up to $55.8 \%$. The main objective of this study was to propose Regression equations for predicting the performance characteristics of externally bonded HyFRP Reinforced Concrete Beams.

\section{EXPERIMENTAL PROGRAMME}

A total of 5 beams were cast and tested for the present research work. The beams were $150 \mathrm{~mm} \times 250 \mathrm{~mm}$ in cross-section and $3000 \mathrm{~mm}$ long. Longitudinal steel ratio adopted for the beam specimens were $0.603 \%$. All beams were casted with M20 grade concrete and tested in four-point bending over a simple span of $2800 \mathrm{~mm}$. The HYSD bars of characteristic strength 545MPa were used for the longitudinal reinforcement. The internal links consisted of mild steel bars of yield strength 310MPa. The specimens were provided with $8 \mathrm{~mm}$ diameter stirrups at $150 \mathrm{~mm}$ spacing. Of the above five beams, one beam served as reference specimen without any strengthening, four beams were strengthened with HyFRP laminates on their soffit. Four combinations of HyFRP laminates were considered in this research, precisely $90 \%$ Glass fibre $+10 \%$ Basalt fibre of thickness, $80 \%$ Glass fibre + 20\% Basalt fibre, 70\% Glass fibre + 30\% Basalt fibre, 60\% Glass fibre $+40 \%$ Basalt fibre, and 2.78, 3.24, 3.86 and $4.24 \mathrm{~mm}$ respectively.Measurement on strength, deformation and failure mode of HyFRP laminated as well as the reference beam. The details of test specimens are presented in Table 1.The properties of HyFRP used in this research study are presented in Table 2.

Table 1 Details of Test Beams

\begin{tabular}{|c|c|c|c|c|c|}
\hline $\begin{array}{l}\dot{0} \\
\dot{\text { म }}\end{array}$ & 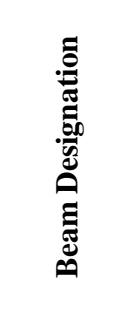 & 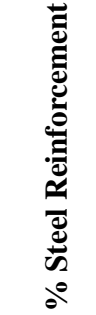 & 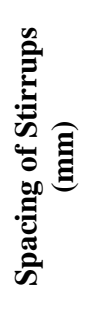 & 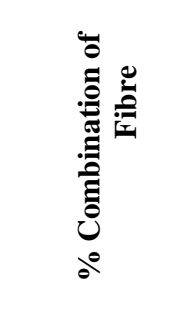 & 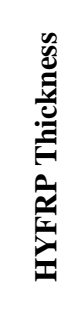 \\
\hline 1. & RB1 & 0.603 & 150 & 0 & 0 \\
\hline 2. & HyGB1 & 0.603 & 150 & $90 \% \mathrm{G}+10 \% \mathrm{~B}$ & 2.78 \\
\hline 3. & HyGB2 & 0.603 & 150 & $80 \% G+20 \% B$ & 3.24 \\
\hline 4. & HyGB3 & 0.603 & 150 & $70 \% \mathrm{G}+30 \% \mathrm{~B}$ & 3.86 \\
\hline 5. & HyGB4 & 0.603 & 150 & $60 \% \mathrm{G}+40 \% \mathrm{~B}$ & 4.24 \\
\hline
\end{tabular}

Table 2 Characteristic Properties of HyFRP laminates

\begin{tabular}{|c|c|c|c|c|c|}
\hline $\begin{array}{l}\dot{z} \\
\dot{\omega}\end{array}$ & 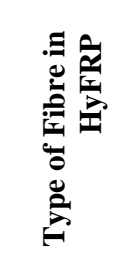 & 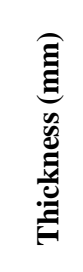 & 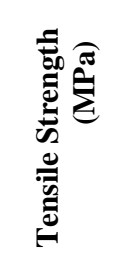 & 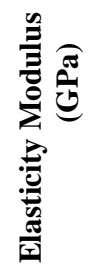 & 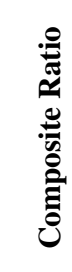 \\
\hline 1. & HyGB1 & 2.78 & 342.53 & 24.6 & \\
\hline 2. & HyGB2 & 3.24 & 372.44 & 26.3 & 1.84 \\
\hline 3. & HyGB3 & 3.86 & 392.38 & 27.9 & 2.15 \\
\hline 4. & HyGB4 & 4.24 & 432.61 & 29.1 & 2.81 \\
\hline
\end{tabular}

The beams strengthened with HyFRP and un-strengthened beams were tested under four point-bending in a loading frame of $500 \mathrm{kN}$ capacity. The beams were supported on hinge at one end and roller at the other end. The deflection measurement upto ultimate stage was accomplished using a specially designed mechanical dial gauge. The crack width was measured and monitored using crack detection microscope with a least count of $0.02 \mathrm{~mm}$ accuracy. Crack development and propagation was monitored during the process of testing. The loading was continued until failure and all the measurements were taken at all stages of loading. The detail of the associated instrumentation for testing is presented in Fig. 1.

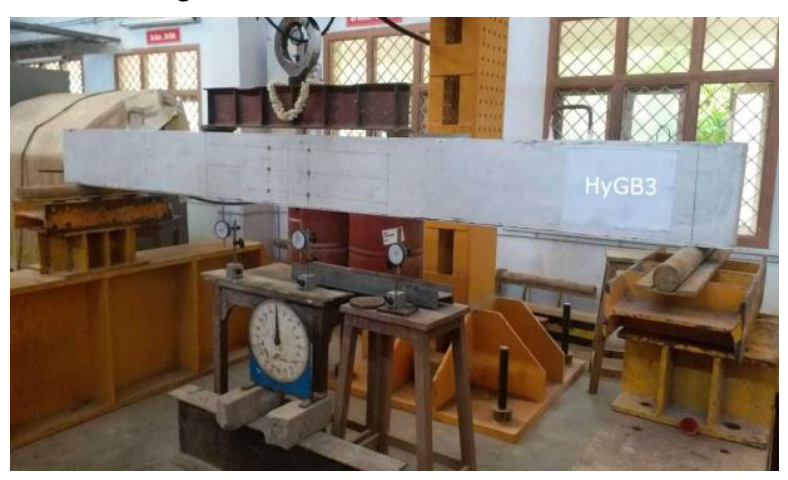

Fig. 1 Experimental Test Set-up

\section{MULTI LINEAR REGRESSION ANALYSIS}

Regression analysis is a statistical tool for the exploration of relationships between the variables. Regression analysis with a single explanatory variable is termed simple regression. Multiple linear regression is a method that allows supplementary factors to enter the analysis distinctly. It is valuable for quantifying the impact of various simultaneous influences upon a single dependent variable. Regression analysis is a procedure for relating known input variables and output parameter using statistical ideologies. The general regression technique is to assume a form of relationship for the input parameters and the results, with a number of unknown coefficients. The unknown coefficients are found out using the data available from experiments or other sources using the Legendre's principle of least squared errors.
Published By:

Blue Eyes Intelligence Engineering and Sciences Publication (BEIESP) 16 (C) Copyright: All rights reserved.

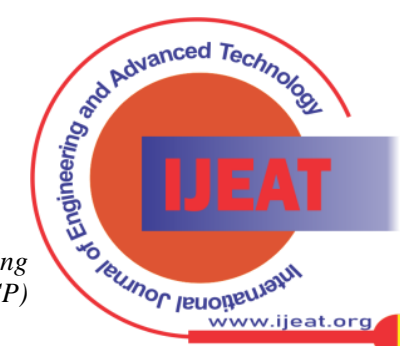
Exploring Innovation 
The mathematical technique used for fitting curves, whether linear or non-linear of the predetermined shape. The purpose of regression is to evaluate the unknown coefficients in an equation.

Regression coefficient is an unknown parameter presented into the equation, to modify the combination of input variables. On solving the regression problem using the code of least squared errors, all the regression coefficients are estimated. Legendre's principle of least squared errors attempts to solve the problem of regression using the condition that the square of the difference between the actual value and the value predicted by the equation should be a minimum. This is accomplished by finding the derivative of the square of the error with reference to each one of the unknown coefficients in the assumed equation. Root Mean Squared Error (RMSE) is the square root of the Mean Squared Error (MSE). This indicates the extent of deviation from the expected value to the higher side or to the lower side. Hence, the RMSE is a better measure of error when compared to the MSE.Multivariate linear regression helps to construct first order equations involving more than one independent variable. The basic formulation for multivariate linear regression is,

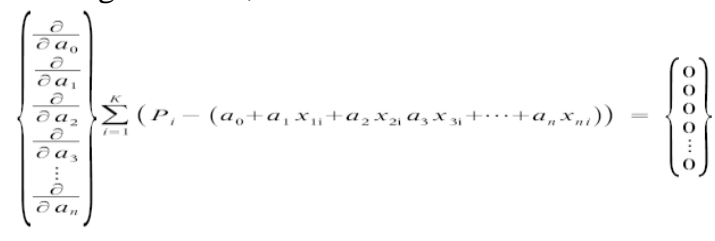

(1) where, $\mathrm{a}_{0} \ldots \mathrm{a}_{\mathrm{n}}$ are the coefficients to be determined, $\mathrm{x}_{1} \ldots \mathrm{x}_{\mathrm{n}}$ are the independent variables, $\mathrm{P}$ is the dependent variable or the actual result value for the set of $i^{\text {th }}$ input data and $K$ is the number data sets available for regression. The above Equation 1 reduces to the following equation which can be solved by summing up the values of independent and dependent variables after carrying out the required operations.

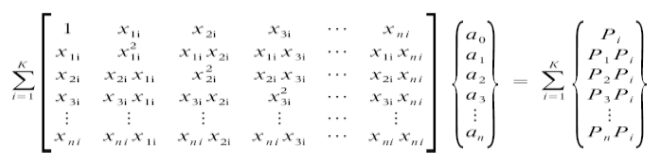

The data used for the regression analysis to predict the regression equation is given in Table 3 and the predicted regression equations are presented in Table 4 . In this analysis the independent variables are thickness of HyFRP, elastic Modulus of HyFRP and tensile strength of HyFRP. The dependent variables considered are load and deflection at various stages, deflection ductility, deflection ductility ratio, energy ductility, energy ductility ratio and maximum crack width.

Table 3 Data Used for the Regression Analysis

\begin{tabular}{|c|c|c|c|c|c|c|c|c|c|c|c|c|c|}
\hline 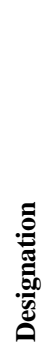 & 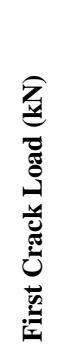 & 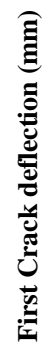 & 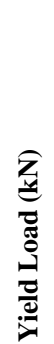 & 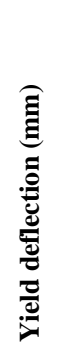 & 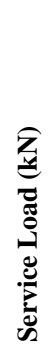 & 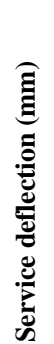 & 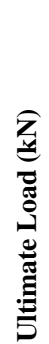 & 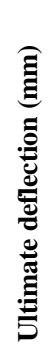 & 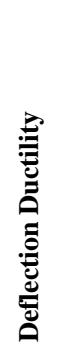 & 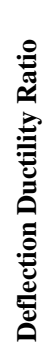 & 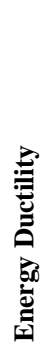 & 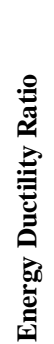 & 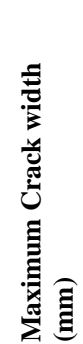 \\
\hline
\end{tabular}

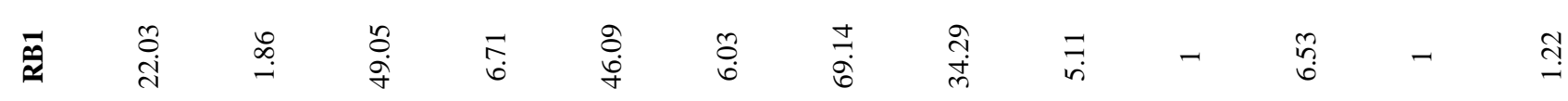

\begin{tabular}{|c|c|c|c|c|c|c|c|c|c|c|c|c|c|}
\hline 包 & $\begin{array}{l}\hat{\sigma} \\
\hat{\omega}\end{array}$ & $\begin{array}{l}\stackrel{0}{\infty} \\
\ddot{n}\end{array}$ & $\begin{array}{l}\text { ڤ } \\
\text { ஸ் }\end{array}$ & 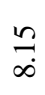 & 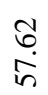 & $\begin{array}{l}\text { டे } \\
\text { ஸे }\end{array}$ & 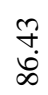 & $\begin{array}{l}50 \\
\dot{0} \\
\text { டे }\end{array}$ & શิ & $\underset{\sim}{\stackrel{\sim}{\sim}}$ & $\stackrel{n}{\stackrel{\sim}{\sigma}}$ & $\stackrel{?}{\stackrel{P}{+}}$ & $\stackrel{\Xi}{ت}$ \\
\hline
\end{tabular}

\begin{tabular}{|c|c|c|c|c|c|c|c|c|c|c|c|c|}
\hline 卷 $N$ & $\begin{array}{l}\text { ?े. } \\
\stackrel{2}{\sim}\end{array}$ & $\stackrel{\vec{\nu}}{\mathrm{v}}$ & $\begin{array}{l}\vec{\nabla} \\
\ddot{\theta}\end{array}$ & 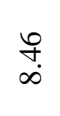 & 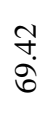 & $\underset{ت}{\overrightarrow{-}}$ & $\begin{array}{l}\underset{+}{J} \\
\stackrel{+}{0}\end{array}$ & $\begin{array}{l}\text { Nิ } \\
\text { Nె }\end{array}$ & ָి & $\stackrel{\text { సิ }}{-}$ & $\begin{array}{l}m \\
\infty \\
0 \\
0\end{array}$ & نْْ \\
\hline
\end{tabular}

\begin{tabular}{|c|c|c|c|c|c|c|c|c|c|c|c|c|c|}
\hline 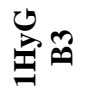 & $\begin{array}{l}m \\
\text { mे } \\
\dot{m}\end{array}$ & $\begin{array}{l}\infty \\
\stackrel{0}{ } \\
ن\end{array}$ & $\begin{array}{l}\text { ठே } \\
\text { मूं }\end{array}$ & $\begin{array}{l}\hat{\wedge} \\
\infty\end{array}$ & $\begin{array}{l}\infty \\
\infty \\
\wedge \\
\wedge\end{array}$ & $\begin{array}{l}\text { જ़ } \\
\text { }\end{array}$ & $\begin{array}{l}m \\
\infty \\
\dot{0} \\
=\end{array}$ & 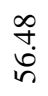 & $\begin{array}{l}\forall \\
\qquad\end{array}$ & 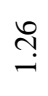 & $\begin{array}{l}\infty \\
\stackrel{-1}{-}\end{array}$ & $\stackrel{\infty}{\infty}$ & $\begin{array}{l}\infty \\
\infty \\
0 \\
0\end{array}$ \\
\hline
\end{tabular}

\begin{tabular}{|c|c|c|c|c|c|c|c|c|c|c|c|c|}
\hline $\begin{array}{l}\text { 芯 } \\
\text { 胥 } \\
\text { 至 }\end{array}$ & $\begin{array}{l}\stackrel{\text { fे }}{\text { Dे }} \\
\text {. }\end{array}$ & 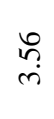 & $\begin{array}{l}\stackrel{9}{+} \\
\dot{\omega}\end{array}$ & $\begin{array}{l}\infty \\
\text { ले } \\
\sigma\end{array}$ & $\begin{array}{l}\mathscr{b} \\
\stackrel{\text { Dे }}{n}\end{array}$ & $\begin{array}{c}m \\
m \\
\infty\end{array}$ & $\begin{array}{l}\stackrel{9}{+} \\
\stackrel{\infty}{\infty}\end{array}$ & $\begin{array}{l}\hat{\theta} \\
\infty \\
\dot{\sigma}\end{array}$ & $\stackrel{\infty}{\stackrel{\infty}{\rightarrow}}$ & تِّ & $\begin{array}{l}\widetilde{o} \\
\stackrel{0}{\infty}\end{array}$ & $\underset{\sim}{\sim}$ \\
\hline
\end{tabular}

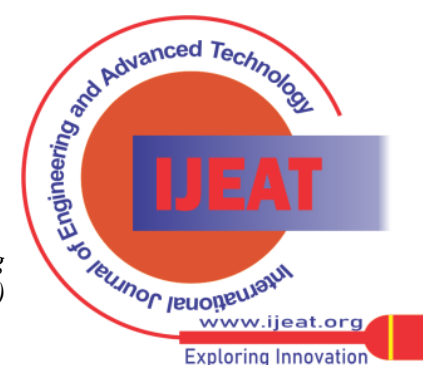




\section{Analytical Predictions on Flexural Strengthening of Reinforced Concrete Beams with Hybrid FRP}

Laminate

\section{RESULTS OF REGRESSION ANALYSIS}

The results of regression analysis in the form of equation for various study parameters related with HyFRPstrengthened reinforced concrete beams for flexural strengthening are presented in Table 4 . The proposed regression equations are enabled to predict analytical results so as to compare with those experimental results. The predicted results indicateda reasonable accuracy.

Table 4 Proposed Regression Equations

\begin{tabular}{|c|c|c|c|c|}
\hline Sl. No. & Prediction Parameter & Equation & Fitness & RMSE \\
\hline 1. & First Crack Load & $22.02+10.49 \mathrm{tk}_{\mathrm{frp}}-.32 \mathrm{fy}_{\mathrm{frp}}+3.56 \mathrm{E}_{\mathrm{frp}}$ & 0.9888 & 0.4229 \\
\hline 2. & $\begin{array}{l}\text { Deflection at First } \\
\text { Crack Load }\end{array}$ & $1.88-2.44 \mathrm{tk}_{\mathrm{frp}}+0.08 \mathrm{fy}_{\mathrm{frp}}-0.80 \mathrm{E}$ & 0.6445 & 0.4843 \\
\hline 3. & Yield Load & $48.96+65.80 \mathrm{tk}_{\mathrm{frp}}-2.34 \mathrm{fy}_{\mathrm{frp}}+25.54 \mathrm{E}_{\mathrm{frp}}$ & 0.9712 & 2.8253 \\
\hline 4. & $\begin{array}{l}\text { Deflection at Yield } \\
\text { Load }\end{array}$ & $6.71+0.53 \mathrm{tk}_{\mathrm{frp}}+0.02 \mathrm{fy}_{\mathrm{frp}}-0.24 \mathrm{E}_{\text {frp }}$ & 0.9997 & 0.0126 \\
\hline 5. & Service Load & $45.97+26.74 \mathrm{tk}_{\mathrm{frp}}-1.31 \mathrm{fy}_{\mathrm{frp}}+15.83 \mathrm{E}_{\mathrm{frp}}$ & 0.8877 & 3.8002 \\
\hline 6. & $\begin{array}{l}\text { Deflection at Service } \\
\text { Load }\end{array}$ & $6.00-6.65 \mathrm{tk}_{\mathrm{frp}}+0.13 \mathrm{fy}_{\mathrm{frp}}-0.84 \mathrm{E}_{\text {frp }}$ & 0.7873 & 0.9052 \\
\hline 7. & Ultimate Load & $68.96+40.12 \mathrm{tk}_{\mathrm{frp}}-1.96 \mathrm{fy}_{\mathrm{frp}}+23.75 \mathrm{E}_{\mathrm{frp}}$ & 0.8876 & 5.7037 \\
\hline 8. & $\begin{array}{l}\text { Deflection at Ultimate } \\
\text { Load }\end{array}$ & $34.26+6.05 \mathrm{tk}_{\mathrm{frp}}-0.42 \mathrm{fy}_{\mathrm{frp}}+5.92 \mathrm{E}_{\mathrm{frp}}$ & 0.9886 & 0.8151 \\
\hline 9. & Deflection Ductility & $5.11+0.28 \mathrm{tk}_{\mathrm{frp}}-0.06 \mathrm{fy}_{\mathrm{frp}}+0.83 \mathrm{E}_{\mathrm{frp}}$ & 0.9723 & 0.0958 \\
\hline 10. & $\begin{array}{l}\text { Deflection Ductility } \\
\text { Ratio }\end{array}$ & $1.00+0.06 \mathrm{tk}_{\mathrm{frp}}-0.01 \mathrm{fy}_{\mathrm{frp}}+0.16 \mathrm{E}_{\mathrm{frp}}$ & 0.9700 & 0.0195 \\
\hline 11. & Energy Ductility & $6.51+3.23 \mathrm{tk}_{\mathrm{frp}}-0.19 \mathrm{fy}_{\mathrm{frp}}+2.49 \mathrm{E}_{\mathrm{frp}}$ & 0.9034 & 0.5865 \\
\hline 12. & Energy Ductility Ratio & $1.00+0.50 \mathrm{tk}_{\mathrm{frp}}-0.03 \mathrm{fy}_{\mathrm{frp}}+0.38 \mathrm{E}_{\mathrm{frp}}$ & 0.9067 & 0.0878 \\
\hline 13. & Maximum Crack Width & $1.22-0.34 \mathrm{tk}_{\mathrm{frp}}+0.01 \mathrm{fy}_{\mathrm{frp}}-0.16 \mathrm{E}_{\mathrm{frp}}$ & 0.8520 & 0.0468 \\
\hline
\end{tabular}

The proposed regression predictions were compared with the experimental test results and depicted through Figs. 2 to 14 exhibit well agreed.

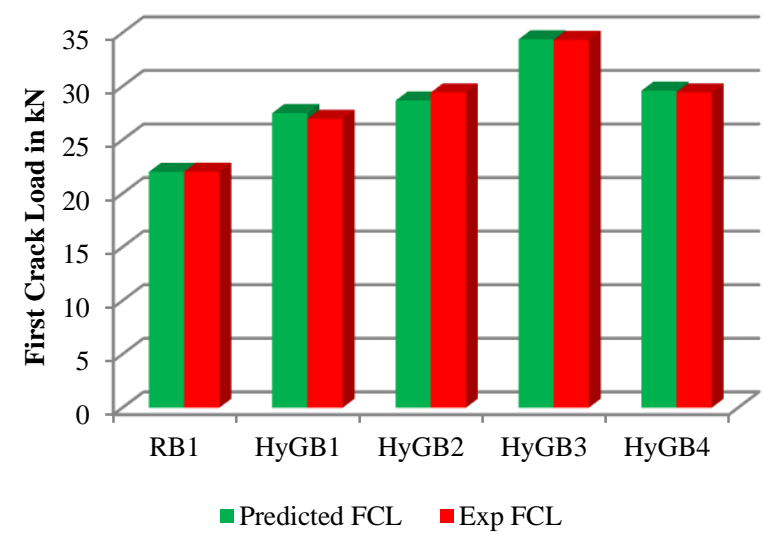

Fig. 2 Experimental vs Predicted results for First Crack Load

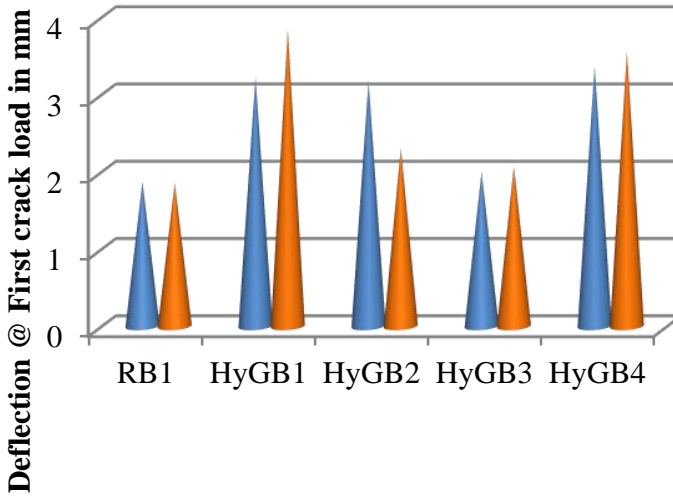

- Predicted Def @ FCL』Exp Def @ FCL

Fig. 3 Experimental vs Predicted results for Deflection at First Crack Load
Published By:

Blue Eyes Intelligence Engineering and Sciences Publication (BEIESP)

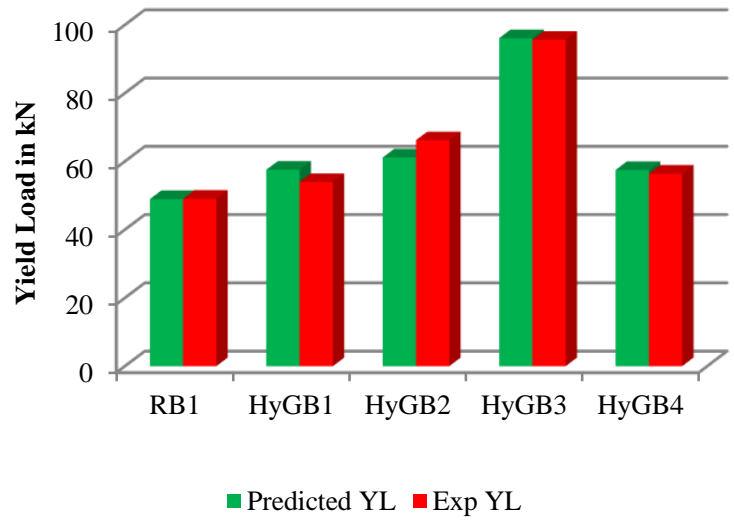

Fig. 4 Experimental vs Predicted results for Yield Load

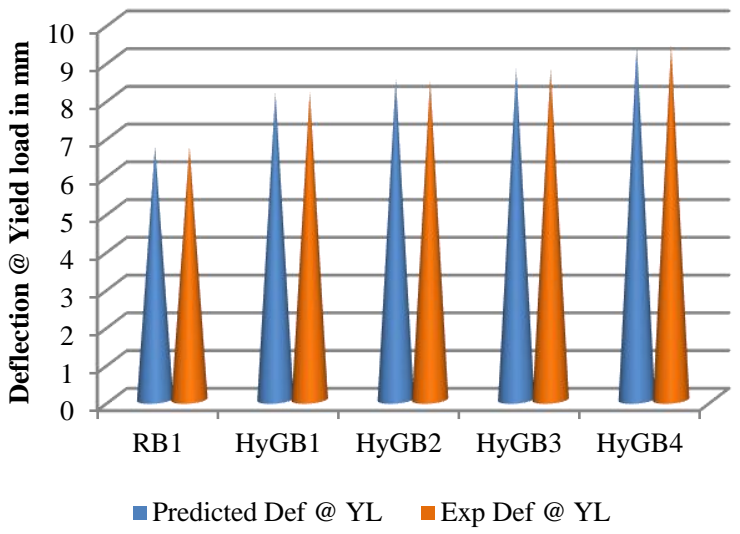

Fig. 5 Experimental vs Predicted results for Deflection at Yield Load

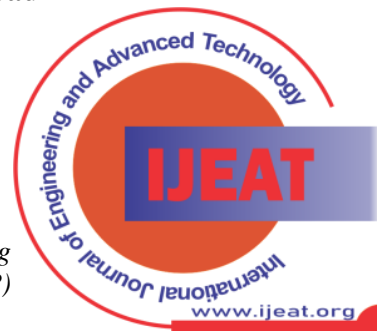




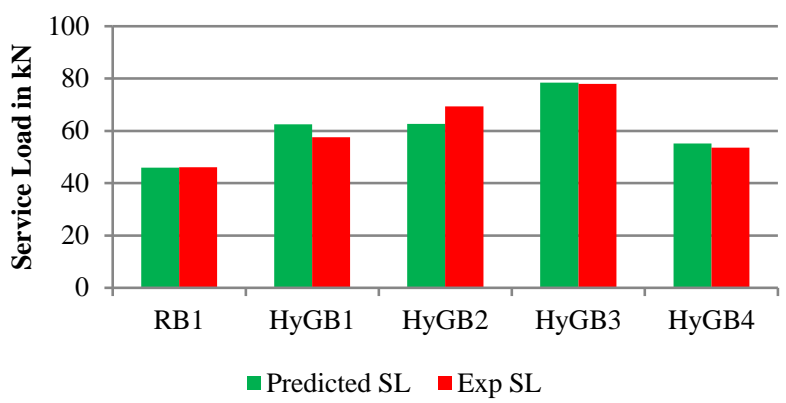

Fig. 6 Experimental vs Predicted results for Service Load

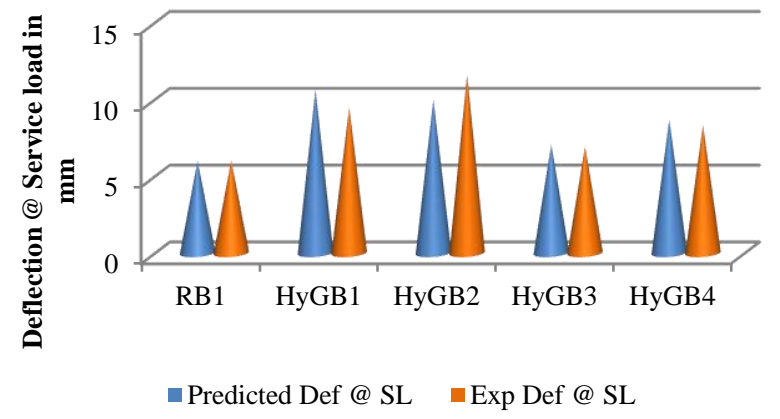

Fig. 7 Experimental vs Predicted results for Deflection at Service Load

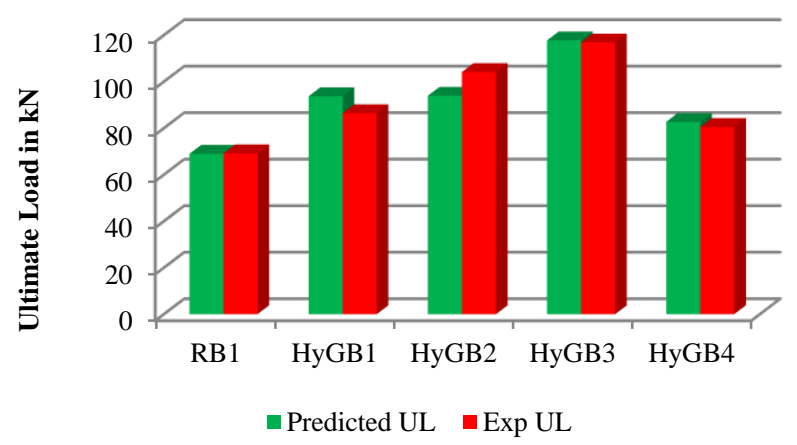

Fig. 8 Experimental vs Predicted results for Ultimate Load

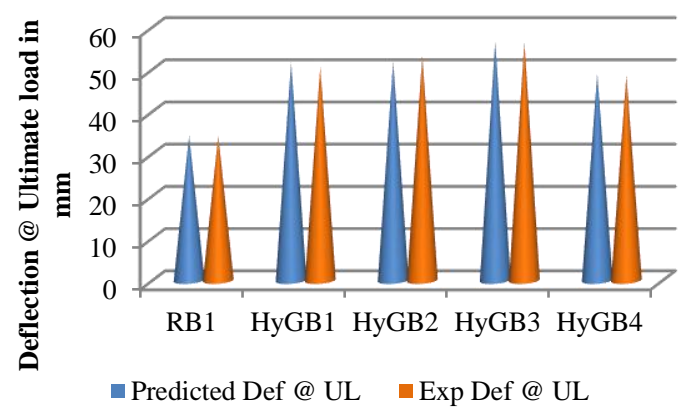

Fig. 9 Experimental vs Predicted results for Deflection at Ultimate Load

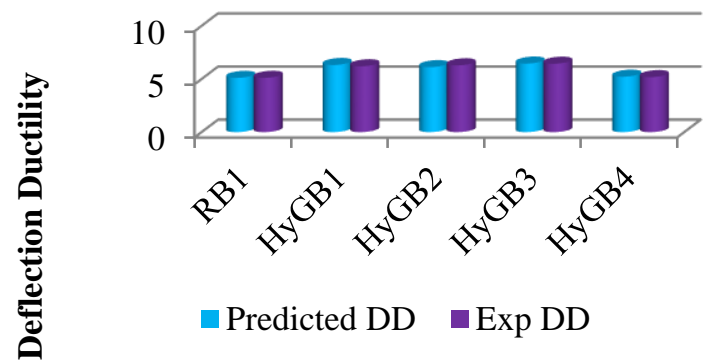

Fig. 10 Experimental vs Predicted results for Deflection Ductility

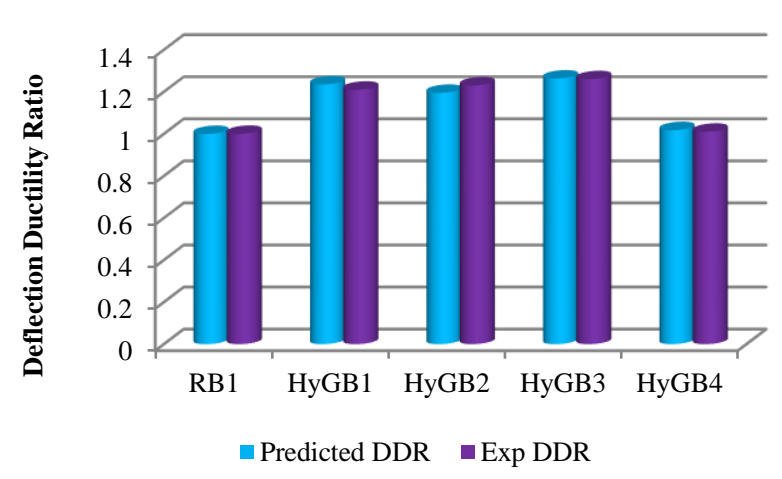

Fig. 11 Experimental vs Predicted results for Deflection Ductility Ratio

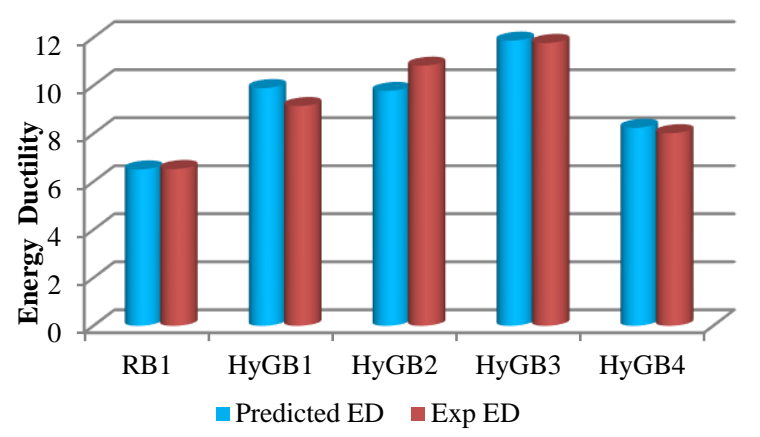

Fig. 12 Experimental vs Predicted results for Energy Ductility

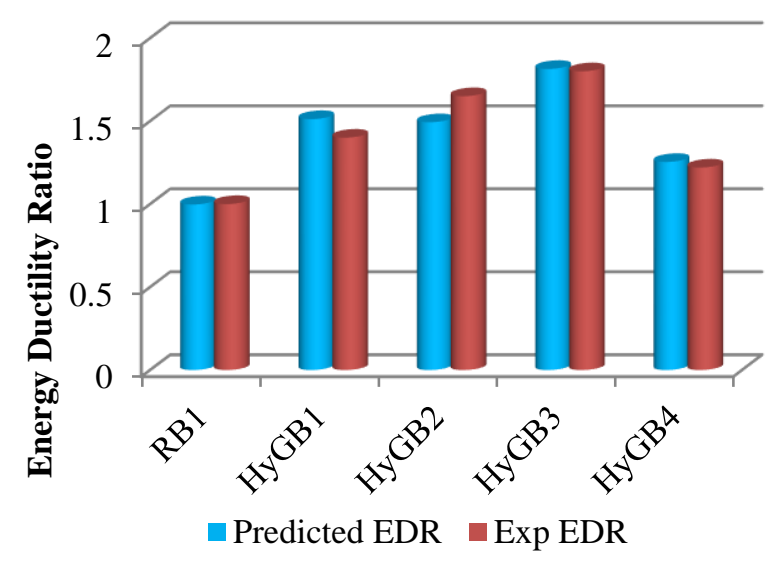

Fig. 13 Experimental vs Predicted results for Energy Ductility Ratio

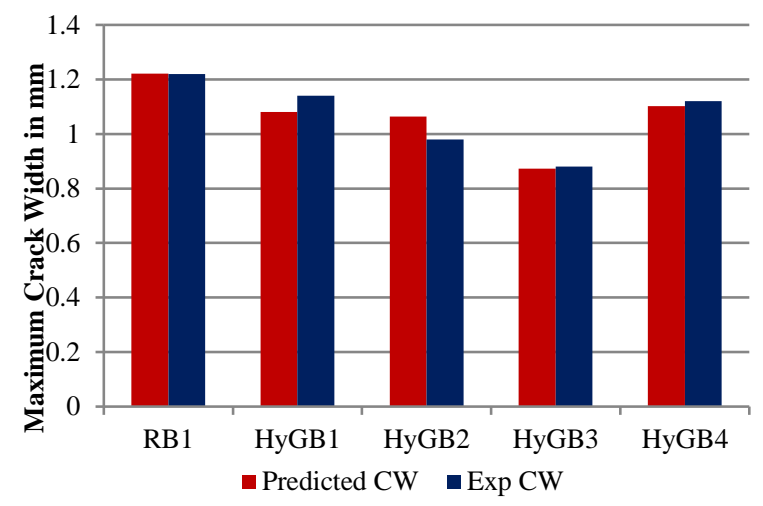

Fig. 12 Experimental vs Predicted results for Maximum Crack Width

Published By:

Blue Eyes Intelligence Engineering and Sciences Publication (BEIESP) 


\section{Analytical Predictions on Flexural Strengthening of Reinforced Concrete Beams with Hybrid FRP Laminate}

\section{CONCLUSIONS}

An observation of the measures of fitness of regression shows that the multivariate linear regression can estimate the prediction values with reasonable levels of accuracy for all study parameters of reinforced concrete beams strengthened with HyFRP laminates. Multiple linear regression proved as a best statistical tool to study the various parameters for the flexural performance of HyFRP laminated RC beams. The analysis results inferred that the overall significance of the regression model was best fitted.The root mean square error values varied from 0.012 to 5.703 . The errors were within a sensible limit and hence the prediction of regression model was well agreed with those of experimental results.

\section{REFERENCES}

1. ACI, 440.2R, (2002), Guide for the Design and Construction of Externally Bonded FRP Systems for strengthening Concrete Structures, American Concrete Institute, Detroit, Michigan, USA, 1-45.

2. Attari, N., Amziane, S., \&Chemrouk, M. (2012). Flexural strengthening of concrete beams using CFRP, GFRP and hybrid FRP sheets. Construction and Building Materials, 37, 746-757.

3. Chellapandian, M., Prakash, S.S. and Sharma, A., (2019). Experimental and finite element studies on the flexural behavior of reinforced concrete elements strengthened with hybrid FRP technique. Composite Structures, 208, pp.466-478.

4. Hawileh, R. A., Rasheed, H. A., Abdalla, J. A., \& Al-Tamimi, A. K. (2014). Behavior of reinforced concrete beams strengthened with externally bonded hybrid fiber reinforced polymer systems. Materials \& Design, 53, 972-982.

5. Ibrahim, M., \&Ebead, U. (2020). Externally bonded hybrid carbon/glass FRP strips for shear strengthening of RC deep beams. Constr. Pathol. Rehabil. Technol. Herit. Manag.(REHABEND 2020), 2237-2245.

6. Sundar, N., Raghunath, P. N., \&Dhinakaran, G. (2016). Flexural behavior of RC beams with hybrid FRP strengthening. International Journal of Civil Engineering and Technology, 7(6), 2016.

7. G. O. Young, "Synthetic structure of industrial plastics (Book style with paper title and editor)," in Plastics, 2nd ed. vol. 3, J. Peters, Ed. New York: McGraw-Hill, 1964, pp. 15-64.

8. W.-K. Chen, Linear Networks and Systems (Book style). Belmont, CA: Wadsworth, 1993, pp. 123-135.

9. H. Poor, An Introduction to Signal Detection and Estimation. New York: Springer-Verlag, 1985, ch. 4.

10. B. Smith, "An approach to graphs of linear forms (Unpublished work style)," unpublished.

11. E. H. Miller, "A note on reflector arrays (Periodical style-Accepted for publication)," IEEE Trans. Antennas Propagat., to be published.

12. J. Wang, "Fundamentals of erbium-doped fiber amplifiers arrays (Periodical style-Submitted for publication)," IEEE J. Quantum Electron., submitted for publication.

13. C. J. Kaufman, Rocky Mountain Research Lab., Boulder, CO, private communication, May 1995.

14. Y. Yorozu, M. Hirano, K. Oka, and Y. Tagawa, "Electron spectroscopy studies on magneto-optical media and plastic substrate interfaces(Translation Journals style)," IEEE Transl. J. Magn.Jpn., vol. 2, Aug. 1987, pp. 740-741 [Dig. 9 $^{\text {th }}$ Annu. Conf. Magnetics Japan, 1982, p. 301].

15. M. Young, The Techincal Writers Handbook. Mill Valley, CA: University Science, 1989.

16. (Basic Book/Monograph Online Sources) J. K. Author. (year, month, day). Title (edition) [Type of medium]. Volume(issue). Available: http://www.(URL)

17. J. Jones. (1991, May 10). Networks (2nd ed.) [Online]. Available: http://www.atm.com

18. (Journal Online Sources style) K. Author. (year, month). Title. Journal [Type of medium]. Volume(issue), paging if given. Available: http://www.(URL)

\section{AUTHORS PROFILE}

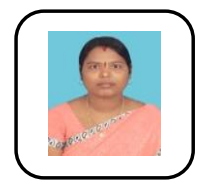

K.PradeebaM.E., Research Scholar Department of Civil and Structural Engineering, Annamalai University, Annamalai Nagar.

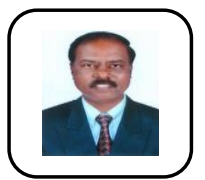

Dr. A. Rajasekaran M.E., Ph.D Professor, Department of Civil and Structural Engineering, Annamalai University, Annamalai Nagar.

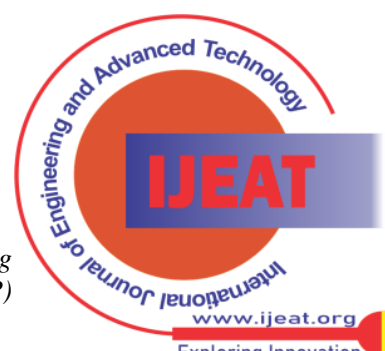

